\title{
Immediate Loading With Flapless GBR in a Compromised Fresh Alveolar Socket
}

CLINICAL INNOVATIONS
PIMENTEL, Gonçalo; MONTENEGRO, Alexandre; PINTO Henrique; TEMPONI, Kamila; OLIVEIRA, Rafael; SANTANA, Ronaldo; MONTENEGRO, Silvana; SOARES, Fernando; MOTA, Carlos.

Brazilian Navy - Rio de Janeiro - BRAZIL

\section{Abstract}

Immediate implant placement is one treatment option for implant therapy following single-tooth extraction in the anterior maxilla. The surgical technique presented here is characterized by tooth extraction without flap elevation, and implant placement in a correct three-dimensional position, simultaneous contour augmentation on the facial aspect with flaplees guided bone regeneration using a double layer of bioabsorbable collagen membrane combined bovine bone graft.

\section{Background and Aim}

The immediate rehabilitation of anterior maxilla is a common procedure in daily practice today. The main objectives of this techique is to reduce the number of surgical procedures, preserve the periodontal architecture and provide an immediate provisionalization to ensure a better aesthetic clinical outcome.

The main hypothesis is to clinically evaluate the possibility of immediate loading with immediate alveolar reconstruction of the buccal wall in the anterior region of the maxilla with flapless guided bone regeneration in cases with buccal alveolar bone defect

\section{Methods and Materials}

The technique consists of minimally traumatic tooth extraction with no flaps to preserve the architecture of periodontal tissues. After clear and rinsing thoroughly the alveolar socket a periosteal detachment is performmed $3 \mathrm{~mm}$ away from the existing alveolar buccal bone defect with tunneling instruments. Bone instrumentation is performed and immediate implant is installed. Before the bone augmentation procedure, a provisional crown is made with the help of a titanium prostheses component. The flapless bone regeneration is obtained by a stretched double layer porcine collagen membrane between the vestibular soft and hard tissue, pulled and suspend by two vestibular sutures and the gap is than filled with a innorganic bone graft.
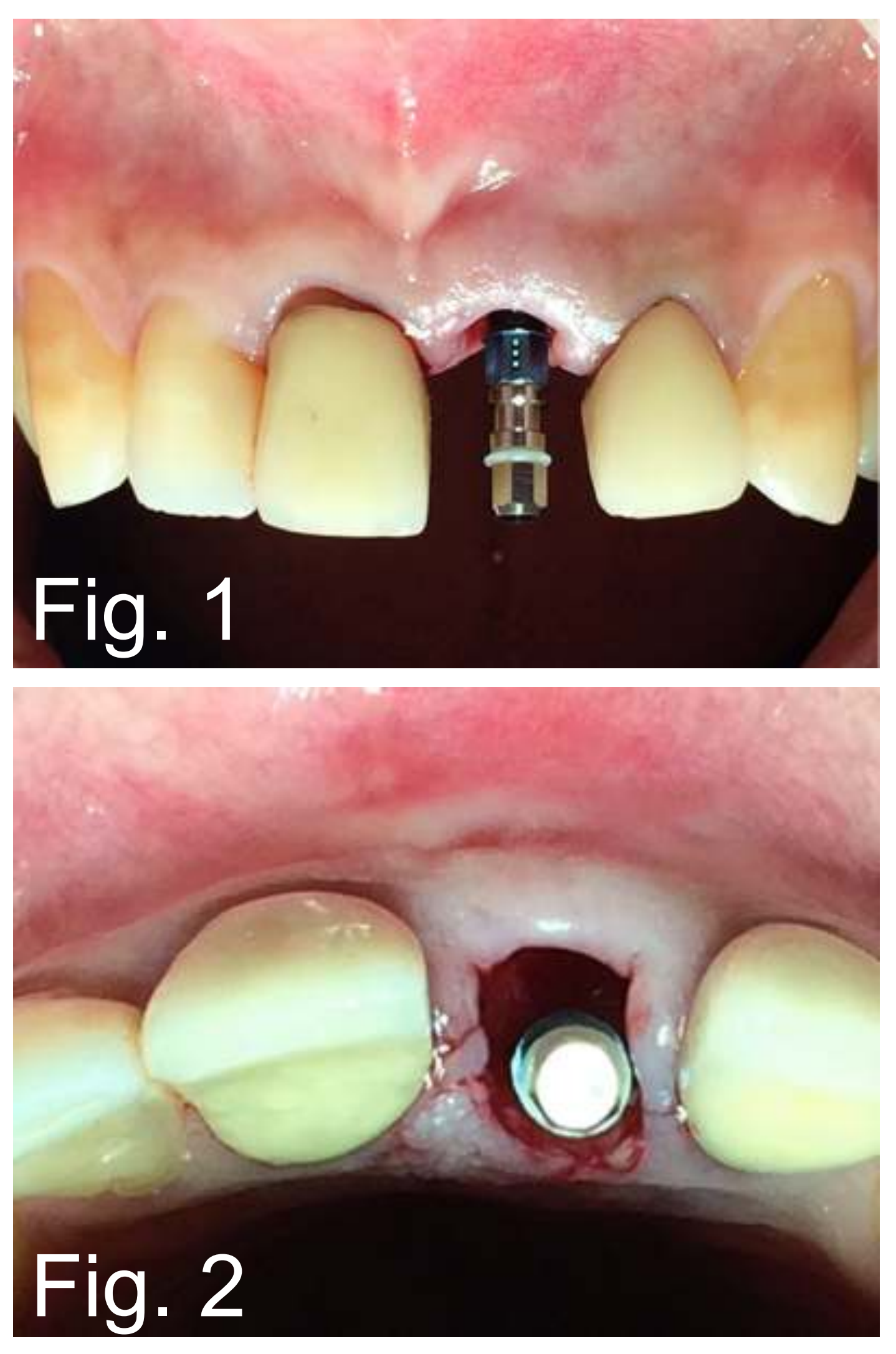

Figures 1 and 2 showing implant placement in correct 3D position

\section{Results}

Preliminary clinical evaluations showed a favorable pink aesthetic score results, with a procedure with low morbidity with no donor sites for hard or soft tissue grafts.
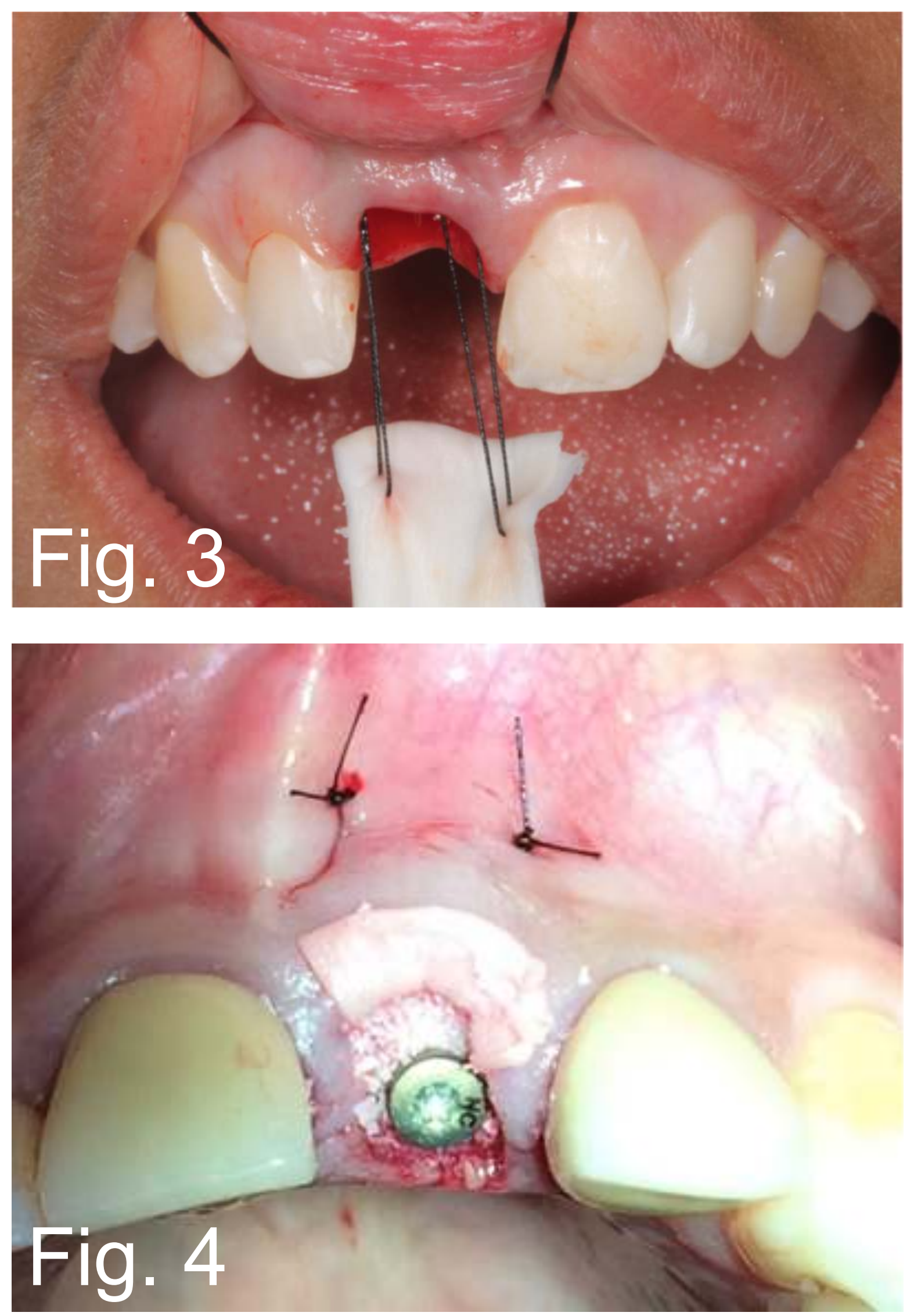

Figures 3 and 4 - fixation of the collagen membrane

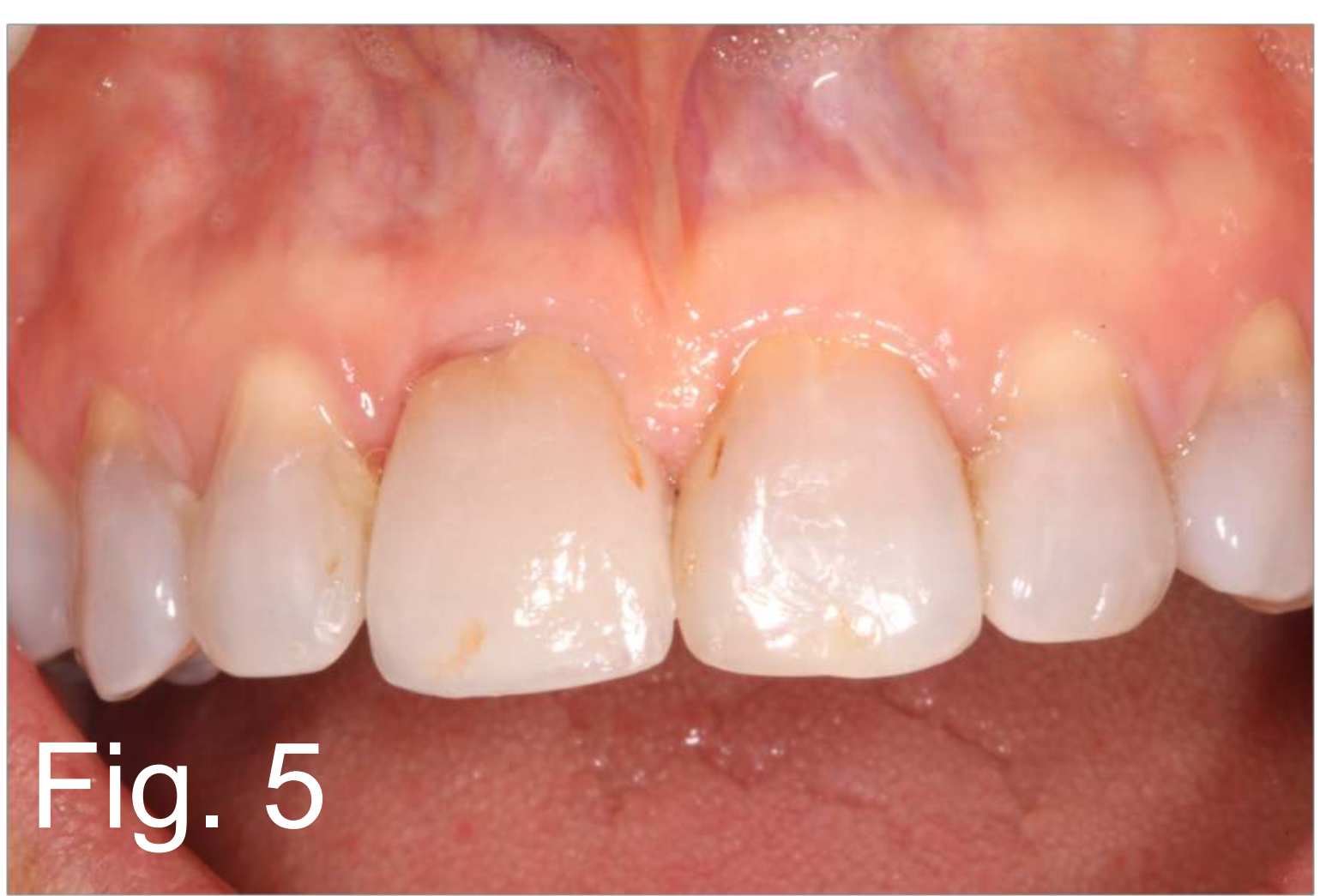

Figures 5 - Flapless ROG in thooth 11, 1 year follow up

\section{Conclusions}

Following the "less is more" Branemark philosophy, the technique showed good results not only in aesthetics aspects but also in patien perception of the treatment. Its possible to rehabilitate the patient with helpless anterior tooth with no donor sites, low morbidity and only one surgical flapless surgical procedure.

\section{References}

1. Lateral ridge augmentation using autografts and barrier membranes: A clinical study with 40 partially edentulous patients. Buser, D. J Oral Maxillofac Surg 1996; 54:420-432

2. Reconstruction of severely resorbed alveolar ridge crests with dental ilpants using a bovine bone mineral for augmentation. Hising, P. Int $J$ Oral Maxillof Implants 2001; 16:90-97.

3. Ridge augmentation by applying bioresorbable membranes and deproteinized bovine bone mineral: a report of twelve consecutive cases. Clin Oral Implants Res 2008;8:279-285

4. Localized ridge augmentation using guided bone regeneration. 1. surgical procedure in the maxila. Buser, D. Int $\mathbf{J}$ Periodontics Restorative Dent 1993; 13:29-45 